\title{
Assessment of parents induced self-medication in paediatric population in rural and urban areas of Ahmedabad, Gujarat
}

\author{
Sanskruti J. Patel, Gurusharan H. Dumra*
}

Department of Pharmacology, AMC MET Medical College, Maninagar, Ahmedabad, Gujarat, India

\author{
Received: 09 February 2020 \\ Revised: 12 March 2020 \\ Accepted: 13 March 2020 \\ *Correspondence: \\ Dr. Gurusharan H. Dumra , \\ Email: gurusharandumra@gmail.com
}

Copyright: (C) the author(s), publisher and licensee Medip Academy. This is an open-access article distributed under the terms of the Creative Commons Attribution Non-Commercial License, which permits unrestricted non-commercial use, distribution, and reproduction in any medium, provided the original work is properly cited.

\begin{abstract}
Background: Self-medication is termed as administration of medications by care-givers without medical consultation. It includes several forms through which the individual themselves or the ones responsible for them decide, without medical evaluation, which drug they will use and in which way for the symptomatic relief and cure of a condition. Objectives of the study was to estimate the overall prevalence of parents induced self-medication, to identify the most commonly used drugs and the reasons of self-medications in rural and urban areas of Ahmedabad, Gujarat.

Methods: This is community based observational cross sectional study was conducted over a period of four months in urban and rural areas of district Ahmedabad under the field practice area of AMC MET Medical College and Sheth LG General Hospital, district Ahmedabad, Gujarat. The study population included children from 5-15 years. The data was collected from the care giver/parents of the children through a pre-validated questionnaire.

Results: Prevalence of self-medication was $86.14 \%$. Most common illness for which self- medication was done was fever in 84 children $(22.16 \%)$ followed by acidity in 72 children (18.99\%). Commonly used drugs were antipyretics, antibiotics and oral rehydration therapy. Previous prescription was used by most of them to procure the drugs and previous experience on efficacy was the most common reason cited.

Conclusions: In this study, the prevalence of parents induced self-medication is quite high. There is a need to strengthen public education regarding self- medication, by mass media and local government authorities.
\end{abstract}

Keywords: Paediatric population, Parent induced, Self-medication

\section{INTRODUCTION}

Self-medication is an important public health problem, practiced across the globe, with a reported prevalence of $27 \%$ in USA, $21 \%$ in Eastern Europe and $0.1 \%$ in Northern and Western Europe. ${ }^{1-6}$ In developing countries, reported self-medication prevalence rates are much higher $-84 \%$ in Pakistan, $78 \%$ in Saudi Arabia, 67\% in Nigeria and $79 \%$ in India. ${ }^{2,7-9}$ In developing countries like India, a large percent of the population comprises of children and they are more vulnerable and susceptible to different diseases. In these countries, where universal access to health care is yet to be achieved, selfmedication is one of the common and preferred modes used by the parents of pediatric population. Despite the existing rules and regulations in India, failure in the strict execution of pharmaceutical regulations in has contributed to easy access to various medications.

Self-medication associated risks not only include inappropriate diagnosis, inappropriate drug choice and augmented polypharmacy but also drug interactions, drug resistance and adverse drug reactions. Risk of drug dependency and drug abuse are also associated with self- 
medication. Others may also include inadequate dosage, unnecessary prolonged drug use and duplication of medication (as individuals could not be able to identify the same drug of different brand) which may lead to serious consequences. Self-medication practice predominantly with non-prescription over the counter drugs contributes to the high burden of irrational drug use. Parents must be aware of the benefits and risks associated with the self-use of medicines.

Keeping this into consideration, this study was carried out with the aim to estimate the overall prevalence of parents induced self-medication, to identify the most commonly used drugs and the reasons of self-medications in rural and urban areas of Ahmedabad, Gujarat.

\section{METHODS}

This community based observational cross sectional study was conducted in urban and rural areas of district Ahmedabad under the field practice area of AMC MET Medical College and Sheth LG General Hospital, district Ahmedabad, Gujarat. In this study, out of the selected area(s) in district, one among many urban and rural colonies were selected by simple random sampling. The urban areas selected were Ishanpur and Khokhra, WardManinagar, District Ahmedabad, State-Gujarat and the rural areas namely Jetalpur village, Naj village and Aslali village, Tehsil-Daskroi, District-Ahmedabad, StateGujarat.

The list of all the children residing in the study area was procured from survey register of the urban health training center (UHTC) and all the concerned rural health centres. House listing was done in the selected urban and rural colony and every fifth house was included in the study. The study population included children from 5 to 15 years of age.

The study was conducted over a period of four months from August 2018 to November 2018 after the approval of Institutional Review Board. Data was collected from either of the parents of these children after explaining them the nature of the study. A written and informed consent was obtained in vernacular language from the parents/ caregivers/ legal guardians before proceeding to a formal structured interview.

The participants were assured that records and data identifying the subject will be kept confidential. Children not accompanied by either of the parent/ caregiver/ legal guardian, those unwilling to participate and also health workers (doctors, nurses, midwives) who have the skills and the right to give medical advice, prescribe and / or advise on the use of medication were excluded from the study.

Data was collected using the questionnaire which was pre-validated by the paediatrician. Gujarati and Hindi version of the proforma was also prepared to facilitate the study especially among the rural population. A recall period of three months prior to the interview was used. Name, age, gender, relationship of the caregiver to the child, area of residence (rural or urban) and socioeconomic status as per the Modified Kuppuswamy scale were noted for all respondents. Parents/caregivers/legal guardians were questioned whether the child was selfmedicated (by them) in the last three months. For those who replied in affirmative, details regarding the illness for which the drug was given, the drugs used, duration, source of drugs, reason for not consulting a doctor and sources of information for dosage decision were noted. Further questions about occurrence of any adverse drug events during self-medication, and whether the respondents read and properly understood the information in the drug package insert about the drug used for the self-medication were part of the questionnaire.

The World Health Organization (WHO) operational definition for self-medication was used, "use of pharmaceutical or medicinal products by the consumer to treat self-recognized disorders or symptoms, the intermittent or continued use of a medication previously prescribed by a physician for chronic or recurring disease or symptom, or the use of medication recommended by lay sources or health workers not entitled to prescribe medicine". ${ }^{10}$ Statistical analysis was done by using appropriate tests. Demographic and clinical variables were expressed in frequencies with their percentage.

\section{RESULTS}

Total 440 children and their parents participated in the study and the response rate was $100 \%$. Out of total 440 responders, 379 children practiced parents induced selfmedication. Mean age of children in present study was 9.28 years. Male to Female ratio was 1:1.44. About $49.32 \%$ (217) children were from urban areas and $50.68 \%$ (223) were from rural areas. The parents of 29 children belonged to upper and upper middle socio economic class while 350 belonged to lower-middle and lower socioeconomic class. Out of 440 children included in the study, 379 had been self-medicated by parents/caregivers in past three months. The prevalence of self-medication in our study was $86.14 \%$ as shown in Table 1 .

The reasons that motivate self-medication were: "the availability of an old prescription and usage of already available medicines of family members" (37.20\%), "saves time, availability of medicines of family members" $(21.10 \%)$, the "high consultation fees" $(17.15 \%)$, "doctor/ clinic far from home" $(09.76 \%)$. Note that multiple answers were possible. The reasons for self-medication are shown in Table 2.

Most common illness for which self-medication was resorted to was fever in 84 children $(22.16 \%)$ followed by acidity in 72 children (18.99\%). Regarding other symptoms motivating self-medication prior consultation, "ear pain, dental pain, runny nose" was the reason for 46 
mothers (13.14\%), "skin disease" for 45 mothers (11.87\%), "vomiting with fever" for 37 mothers $(9.76 \%)$, "eye infection and diarrhoea" for 31 mothers (8.18\%). Other symptoms were "diarrhoea with stomach ache" $(n=23)$, "pain in joints along with fever" $(n=13)$, "respiratory infections" $(\mathrm{n}=10)$ followed by "headache with body pain" and "genital or urinary tract infection" $(\mathrm{n}=08)$, as mentioned in Table 3.

Table 1: Distribution of study subjects according to self-medication practices $(\mathrm{N}=440)$.

\begin{tabular}{|lll|}
\hline $\begin{array}{l}\text { Parameters/gender } \\
\text { distribution among study } \\
\text { subject }\end{array}$ & $\begin{array}{l}\text { Self-medication } \\
\text { Yes }(\%)\end{array}$ & $\begin{array}{l}\text { No } \\
\text { N (\%) }\end{array}$ \\
\hline Total responders (n=440) & $\begin{array}{l}379 \\
(86.14)\end{array}$ & $61(13.86)$ \\
\hline Male child (n=180) & $\begin{array}{l}145 \\
(80.55)\end{array}$ & $35(19.44)$ \\
\hline Female child (n=260) & $234(90)$ & $26(10)$ \\
\hline Rural (n=223) & 189 & 34 \\
\hline Urban (n=217) & 190 & 27 \\
\hline $\begin{array}{l}\text { Socio-economic status of parents as per the } \\
\text { modified kuppuswamy classification }\end{array}$ & \\
\hline $\begin{array}{l}\text { Upper and upper middle } \\
\text { class (n=45) }\end{array}$ & 29 & 16 \\
\hline $\begin{array}{l}\text { Lower middle class and } \\
\text { lower class (n=395) }\end{array}$ & 350 & 45 \\
\hline $\begin{array}{l}\text { Education status of parents } \\
\text { Illiterate }\end{array}$ & 46 & 04 \\
\hline Primary school educated & 75 & 18 \\
\hline $\begin{array}{l}\text { High school educated } \\
\text { Diploma/graduate }\end{array}$ & 213 & 32 \\
\hline Higher studies/postgraduate & 18 & 03 \\
\hline
\end{tabular}

Table 2: Reasons for self-medication $(n=379)$.

\begin{tabular}{|llll}
\hline $\begin{array}{l}\text { Reasons to self- } \\
\text { medicate the child }\end{array}$ & Rural & Urban & Total N (\%) \\
\hline $\begin{array}{l}\text { Doctor/clinic far } \\
\text { from home }\end{array}$ & 21 & 16 & $37(9.76)$ \\
\hline $\begin{array}{l}\text { High fees of } \\
\text { doctor, saves time* }\end{array}$ & 13 & 17 & $30(07.91)$ \\
\hline $\begin{array}{l}\text { No trust in doctor } \\
\text { Saves time, }\end{array}$ & 02 & 03 & $05(01.31)$ \\
$\begin{array}{l}\text { availability of } \\
\text { medicines of family } \\
\text { members* }\end{array}$ & 39 & 41 & $80(21.10)$ \\
\hline $\begin{array}{l}\text { Availability of an } \\
\text { old prescription }\end{array}$ & 11 & 10 & $2(5.54)$ \\
\hline $\begin{array}{l}\text { The availability of } \\
\text { an old prescription } \\
\text { and usage of } \\
\text { already available } \\
\text { medicines of family } \\
\text { members* }\end{array}$ & 75 & 66 & $141(37.20)$ \\
\hline $\begin{array}{l}\text { High fees of doctor } \\
\text { *multiple response. }\end{array}$ & 28 & 37 & $65(17.15)$ \\
\hline
\end{tabular}

Table 3: Symptoms reported for self-medication $(n=379)$.

\begin{tabular}{|ll|}
\hline $\begin{array}{l}\text { For which disease you have taken } \\
\text { self-medication in last three } \\
\text { months? }\end{array}$ & Numbers $(\%)$ \\
\hline $\begin{array}{ll}\text { Headache, body pain* } \\
\text { Eye infection, diarrhoea* }\end{array}$ & $08(2.11)$ \\
\hline $\begin{array}{l}\text { Ear pain, dental pain, runny } \\
\text { nose* }\end{array}$ & $31(8.18)$ \\
\hline Fever, pain in joints* & $46(12.13)$ \\
\hline Skin disease & $13(3.43)$ \\
\hline Acidity & $45(11.87)$ \\
\hline Genital/urinary tract infection & $72(18.99)$ \\
\hline Fever, vomiting* & $08(2.11)$ \\
\hline Diarrhoea, stomach ache* & $37(9.76)$ \\
\hline Fever & $23(6.06)$ \\
\hline Respiratory infection & $84(22.16)$ \\
\hline
\end{tabular}

*multiple response.

Among the 379 parents practicing self-medication on their children, only 317 could show the residual/remnant medicine strip/packaging/empty bottle during the interview/questionnaire filling whereas 62 of them could only recollect in memory, the dosage form of the drug given by them to the child and not the actual drug name. Thus, these 62 were excluded from the table of most commonly used medicines.

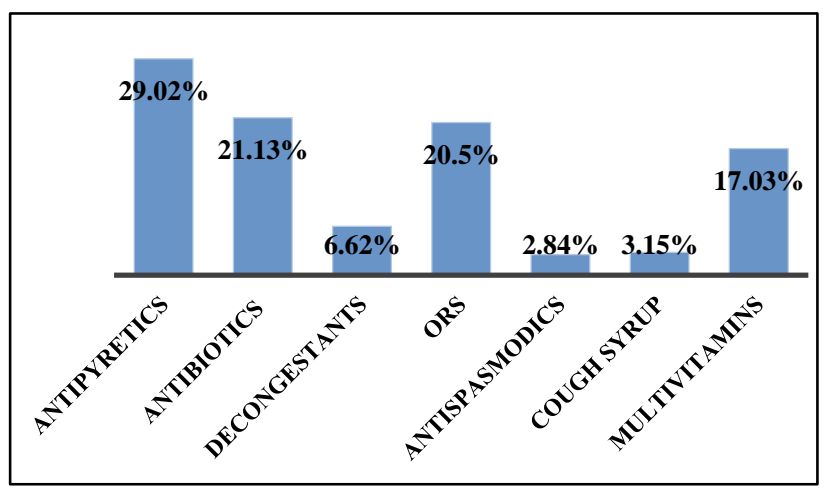

Figure 1: Commonly used drugs for self-medicating the child $(n=317)$.

Most commonly used drug was paracetamol which was used in 92 children (29.02\%). Antibiotics was used by 67 children $(21.13 \%)$ and oral rehydration solution (ORS) therapy by 64 children $(20.50 \%)$ followed by decongestants by $21(06.62 \%)$ children. Although prescription is not required to procure ORS, it was found to be one of the commonly used entity to self-treat the child's condition. The common drugs used for selfmedication in children are shown in Figure 1. Single drug usage by 233 children $(61.47 \%)$ and multiple drug usage was seen in 146 children $(52.33 \%)$. Mean duration of selfmedication was 2.5 days.

Most common factor that was considered by parents while selecting drug for self-medication was price $(47.80 \%)$ 
followed by type of medicine (32.45\%) and pharmaceutical company (14.51\%). While $05.54 \%$ parents considered both price and type of medicine for self-medication. The selection of a particular brand was greatly influenced by having the old prescription of doctor in $239(63.06 \%)$ followed by friends/family/neighbour's advice in $74(19.52 \%)$, recommendations by the pharmacy store in $35(9.23 \%)$ and based on previous experience with the drugs used for disease in question in 31 (8.18\%).

Majority of the parents (313 (82.58\%)) preferred allopathic drugs to self-medicate their children whereas $16.09 \%$ opted for homeopathic medicine and $1.32 \%$ used ayurvedic drug to treat their child's ailment. Most common source to obtain/procure the $\operatorname{drug}(\mathrm{s})$ was pharmacy store in 310 parents $(81.80 \%)$. Friends and family were the source in 41 parents $(10.81 \%)$, followed by health care workers in $28(07.38 \%)$

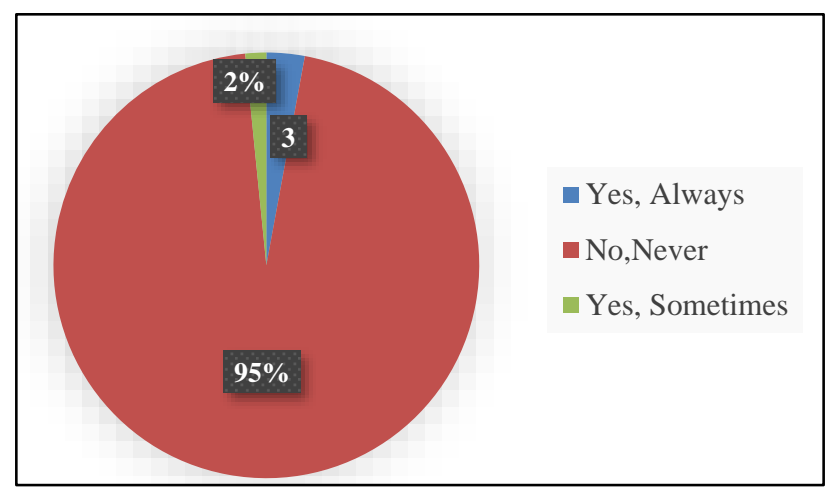

Figure 2: Do you check the prescribing information before self-medicating the child? $(n=379)$.

As these drug dispensing facilities are available on one's door step, it is a common practice among the consumers to refill their medication without the consultation of the prescribing doctors and also to self-treat the selfdiagnosed ailments of their children. It is of even more importance for the parents to read and follow the specific and complete information regarding the marketed medicinal products available in the form of drug package insert.

In present study, it was found that majority of the parents $(95 \%)$ did not bother to read/check the prescribing information before self-medicating their child. This would ultimately increase the number of adverse drug reactions resulting from medication errors affecting this vulnerable group of population.

The common dose deciding factor for self-medication among $139(36.67 \%)$ parents was found to be the previous doctor's visit prescription for any child other than the one in question in the family followed by previous doctor's visit prescription for that particular child in question, noted in $111(29.28 \%)$. Whereas $66(17.41 \%)$ used the self-medication dose as suggested by unauthorized nonqualified non allopathic practitioner. The dose of the medicine given by the parents based on self- assessment depending on the severity of the condition/disease was the reason in $54(14.24 \%)$ and dose advised by neighbours and/ relatives in $09(2.37 \%)$ as shown in Table 4.

Table 4: Factors which influence in deciding the dose of self-medication $(n=379)$.

\begin{tabular}{|l|l|}
\hline $\begin{array}{l}\text { How do you decide the dose for self- } \\
\text { medication? }\end{array}$ & $\begin{array}{l}\text { Numbers } \\
(\%)\end{array}$ \\
$\begin{array}{l}\text { Previous doctor's visit prescription } \\
\text { for this particular child }\end{array}$ & $111(29.28)$ \\
\hline $\begin{array}{l}\text { Previous doctor's visit prescription } \\
\text { for any child other than this in the } \\
\text { family }\end{array}$ & $139(36.67)$ \\
\hline $\begin{array}{l}\text { Self- assessment depending on } \\
\text { severity of condition/disease }\end{array}$ & $54(14.24)$ \\
\hline $\begin{array}{l}\text { Unauthorized non- qualified non } \\
\text { allopathic practitioner }\end{array}$ & $66(17.41)$ \\
\hline \begin{tabular}{l} 
Neighbours/ relatives \\
\hline
\end{tabular} & $9(2.37)$ \\
\hline
\end{tabular}

Out of all the children self-medicated by their parents $(n=379), 23$ children experienced adverse event. The frequently encountered adverse events were diarrhoea, skin rash and headache. In particular, two child patients from the same family reported peculiar adverse eventboth following the use of medicine which was a part of post cataract medication, prescribed initially for their grandmother. One male patient was 6 years old who complained of blurred vision along with severe headache following the usage of mydriatic eye drops prescribed to their grandmother. Whereas another 14 years old female developed skin rash following ingestion of paracetamol and an antibiotic. Of all the children who suffered adverse event, 13 were taken to primary health centre and 6 were taken to private health settings by their parents for the further management of condition whereas parents of 2 children stopped giving self-prescribed medication and improvement was noted.

\section{DISCUSSION}

Management of childhood illness is different from that of adult diseases. Medications given to children by parents without medical prescription and supervision should be cautiously used and constantly monitored. The dose and frequency of a drug used in a paediatric patient differs from that in an adult individual. These irrational practices by the parents to treat common ailments may lead to manifest some of very serious side effects which may contribute to high incidence of morbidity among young children. In this study the overall prevalence of selfmedication was found to be $86.14 \%$. In accordance to other studies present study revealed a slightly higher prevalence of self-medication in the urban areas. ${ }^{11,12}$ The variation between and within countries is due to the use of different operational definitions of self-medication, difference in health seeking behaviour of people, various socio-cultural factors, relative prevalence and the seasonal variation of illnesses. ${ }^{11-13}$ 
In our study it was noted that majority $(86.54 \%)$ were the mothers, who preferred to self-medicate their children rather than considering to take them to the hospital for the treatment. This is possibly due to the fact that majority of the males are out of their homes in search of work and it is the women (mothers) that take immediate care of the children and are involved in administering home-based or other remedies in case of their ill health. Gupta et al have reported similar data, though their study involved only an urban slum community. ${ }^{14}$ Nazir et al in their study found prevalence of parents induced self-medication practices in $57 \%$ of children aged under five years. ${ }^{15}$

Self-medication provides a cheap alternative to people who cannot afford to pay medical practitioners. Thus, self- medication is often the first response to any illness among people with low socio economic class. Not surprisingly, in this study, the prevalence of selfmedication was highest in the lower-middle and low socio economic class section (as per modified Kuppuswamy classification).

The main reason for which children were self-medicated in this study was the availability of an old prescription and usage of already available medicines of family members in $37.20 \%$ of responders which is slightly higher $(32.9 \%)$ than the one reported by Garofalo et al. ${ }^{16}$ Although the commonest reason in their study showed that $84 \%$ of the parents felt illness were too mild and did not feel the need to see the doctor. ${ }^{16}$ Study observation noted by Nazir et al suggests monetary constraints as the main reason among $44 \%$ parents whereas in present study only $5.01 \%$ parents felt the need to self-medicate their child for minor illness instead of paying high fees of doctor consultation. ${ }^{15}$

Ignorance is bliss and little knowledge is certainly a dangerous thing. This was amply reflected in our study that revealed the highest prevalence of self- medication in high school educated and primary school educated. This is a dangerous proposition as most of the respondents were high school educated, which reflects the general scene of the population. As expected, the prevalence was lowest among the postgraduates as they were well aware of the ill effects of self-medication. Nazir et al and Borah et al have reproduced similar data. ${ }^{15,17}$

The commonest illnesses that led to self-medication in this study were fever $(22.16 \%)$ followed by acidity (18.99\%). In Borah et al study, it was found that the most common self-treated illness by parents is acute respiratory infection in $26.6 \%$ whereas we had only $2.63 \%$ paediatric patients who had been treated by their parents for respiratory infection. ${ }^{17}$ Due to the seasonal and regional variations between and within countries, the occurrence of these illnesses may vary. Nazir et al noted about 37\% diarrheal diseases and $13 \%$ pain abdomen as ailments self-treated by the parents and on the other we had $6.06 \%$ patients treated for combined complaints of abdominal pain and diarrhoea by their parents..$^{15}$
Results in present study shows that pharmacy store/ pharmacist $(81.80 \%)$ was the commonest source of obtaining the drug and drug related information whereas the results reported by Aslam et al had only $7 \%$ parents using pharmacy store/ pharmacist to procure the drug. 18 This suggests that a strict periodic invigilation should be carried out to assess the knowledge of the pharmacist and/or the personnel responsible for dispensing drugs at such stores.

The most common drug to be used by the study population in this study were $29.02 \%$ antipyretics which is in accordance with the study result reported by Borah et al. ${ }^{17}$ Various community based studies had similar observations. ${ }^{19,20}$ Nazir et al in their study found antibiotics as the commonest drug used to practice selfmedication in $52.56 \% .{ }^{15}$ About $21.13 \%$ parents in this study preferred to give antibiotics to their young ones which is lower than the $26.7 \%$ as noted by Garofalo et al and higher than the one reported by Borah et al. ${ }^{16,17} \mathrm{~A}$ worrisome aspect of the scenario is that most of the respondents did not give proper dose of antipyretic (paracetamol) and antibiotics. In this study, 90\% of the respondents consumed antibiotic drugs till symptomatic relief was achieved. The duration of self-medication varied from two days to more than a week in some cases. This may be considered as a contributory factor to the emerging drug resistance.

About $82.58 \%$ respondents in our study selected allopathy preparations to self-medicate their children. Madhu Borah et al in their study had $32.5 \%$ parents using ayurvedic medicines which in comparison to present study is quite higher. ${ }^{17}$ Zaki et al found high prevalence of traditional therapy and non- prescription medication use among infants. $^{21}$

While practicing self-medication especially in this particular vulnerable population, it becomes obligatory for the parents to have an adequate appropriate drug related knowledge. Any deviation from the same may lead to occurrence of adverse event. In study, $6.06 \%$ children had experienced adverse drug reaction while the incidence is $20 \%$ reported as development of ADRs during the treatment in Borah et al. ${ }^{17}$

The limitation of the study included recall bias as it was self-reported data. Also, our study had smaller sample size so the results cannot be generalized on a larger scale.

\section{CONCLUSION}

In the study, it was found that the prevalence of parents induced self-medication is quite high. Antipyretics and antibiotics are commonly used drugs to self-medicate the children. Various studies need to be carried out to know the magnitude as well as causal factors precipitating selfmedication. This study highlights the urgent need of public education regarding self- medication, by mass media and local government authorities. Information, 
education and communication activities should be strengthened to encourage public to avail health services from qualified professionals. There is also a need to strengthen the primary and secondary healthcare systems in order to restrict self-medication.

\section{Funding: No funding sources}

Conflict of interest: None declared

Ethical approval: The study was approved by the Institutional Ethics Committee

\section{REFERENCES}

1. Sahebi L, Vahidi R. Self-medication and storage of drugs at home among the clients of drugstores in Tabriz. Curr Drug Saf. 2009;4(2):107-12.

2. Afridi M, Rasool G, Rabia Tabassum R, Shaheen M, Siddiqullah, Shujauddin M. Prevalence and pattern of self-medication in Karachi: a community survey. Pak J Med Sci. 2015;31(5):1241-5.

3. Martins A, Miranda A, Mendes Z, Soares MA, Ferreira P, Nogueira A. Self-medication in a Portuguese urban population: a prevalence study. Pharmacoepidemiol Drug Saf. 2002;11:409-14.

4. Grigoryan L, Burgerhof J, Ruskamp HF, Degener JE, Deschepper R, Monnet DL, et al. Is self-medication with antibiotics in Europe driven by prescribed use? J Antimicrob Chemother. 2007;59:152-6.

5. Grigoryan L, Ruskamp HF, Burgerhof J. Selfmedication with antimicrobial drugs in Europe. Emerging Infect Dis. 2006;12(3):452-9.

6. Goldsworthy R, Schwartz N, Mayhorn C. Beyond abuse and exposure: framing the impact of prescription-medication sharing. Am J Public Health. 2008;98(6):1115-21.

7. Rasheed A, Yagoub U, Alkhashan H, Abdelhay O, Alawwad A, Aboud A, et al. Prevalence and predictors of self-medication with antibiotics in $\mathrm{Al}$ Wazarat Health Center, Riyadh City, KSA. Biomed Res Int. 2016;16:3916874.

8. Oshikoya K, Senbanjo I, Njokanma O. Selfmedication for infants with colic in Lagos, Nigeria. BMC Pediatri. 2009;9:9.

9. Kumar N, Kanchan T, Unnikrishnan B, Rekha T, Mithra P, Kulkarni V, et al. Perceptions and practices of self-medication among medical students in coastal South India. PLoS One. 2013;8(8):e72247.

10. World Health Organization. Guidelines for the regulatory assessment of medicinal products for use in self-medication. Geneva: World Health Organization; 2000. Available at: http:// apps.who.int/ medicinedocs/pdf/. Accessed on 12 December 2019.

11. Wijesinghe PR, Jayakody RL, Seneviratne RS. Prevalence and predictors of self-medication in a selected urban and rural district of Sri Lanka. Asia J Public Health. 2012;1(1):28-41.

12. Tomson G, Sterky G. Self-prescribing by way of pharmacies in three Asian developing countries. Lancet. 1986;132(8507):620-2.

13. Lam CLK, Catarivas MG, Munro C, Lauder IJ. Selfmedication among Hong-Kong Chinese. Soc Sci Med. 1994;39(12):1641-47.

14. Gupta P, Bobhate PS, Shrivastava SR. Determinants of self-medication practices in an urban slum community. Asian J Pharm Clin Res. 2011;4(3):54-7.

15. Saima N, Goel K, Mittal A, Singh J, Goel R, Rashid A. Parent induced self-medication among under five children: an observational cross sectional study. Preventive Med Bullletin. 2015;4:81-6.

16. Garofalo LG, Gabriella A. (2015). Self-medication practices among parents in Italy. Bio Med Res Int. 2015;58:65-8.

17. Borah M. A community-based cross-sectional study on the use of medication among young children in the rural areas of Assam. J Ntr Univ Health Sci. 2018;7:103-7.

18. Muhammad A, Muhammad J, Daniyal M, Muhammad Z. Parent-based self-medication in Pakistani children: a qualitative cross-sectional survey. Bangladesh J Medical Science. 2016;15:33-9.

19. Hoan le T, Chuc NT, Ottosson E, Allebeck P. Drug use among children under 5 with respiratory illness and/or diarrhoea in a rural district of Vietnam. Pharmacoepidemiol Drug Saf. 2009;18:448-53.

20. Keshari SS, Kesarwani P, Mishra M. Prevalence and pattern of self-medication practices in rural area of Barabanki. Ind J Clin Pract. 2014;25:636-9.

21. Zaki A, Fattah AM, Bassili A, Arafa M, Bedwani R. The use of medication in infants in Alexandria, Egypt. East Mediterr Health J. 1999:5;320-7.

Cite this article as: Patel SJ, Dumra GH.

Assessment of parents induced self-medication in paediatric population in rural and urban areas of Ahmedabad, Gujarat. Int J Basic Clin Pharmacol 2020;9:776-81. 